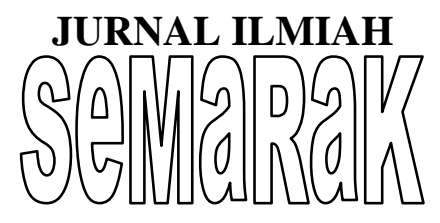

P-ISSN 2615-6849

Jurnal Semarak,Vol. 1,No.1,Februari 2018, Hal (42-53)

@Prodi Manajemen Fakultas Ekonomi Universitas Pamulang

\title{
PENGARUH GAYA KEPEMIMPIAN DAN LINGKUNGAN KERJA FISIK TERHADAP KEPUASAN KERJA PADA PT. BREMA BRATA
}

\author{
Feb Amni Hayati \\ Dosen Fakultas Ekonomi Universitas Pamulang \\ Email: amni_feb@yahoo.com
}

\begin{abstract}
Abstrak
Tujuan penelitian ini untuk mengetahui seberapa besar pengaruh gaya kepemimpinan dan lingkungan kerja fisik terhadap kepuasan kerja karyawan pada PT. Brema Brata.

Jenis penelitian merupakan penelitian kuantitatif dianalisis menggunakan statistik penulis menjadikan karyawan PT. Brema Brata sebagai populasi totalnya berjumlah 66 karyawan.. Analisis data menggunakan SPSS Versi 22. Teknik uji sampling menggunakan metode sensus dan teknik pengambilan data diantaranya uji validitas, uji reliabilitas, uji asumsi klasik dan uji regresi linear berganda serta uji hipotesis.

Secara umum hasil pengujian variabel gaya kepemimpinan dan lingkungan kerja fisik mempunyai pengaruh yang signifikan terhadap kepuasan kerja di PT. Brema Brata. Hal ini berarti hipotesis dapat diterima, karena gaya kepemimpinan dan lingkungan kerja memiliki pengaruh positif terhadap kepuasan kerja. Diantara dua variabel,pengaruh paling signifikan adalah variabel gaya kepemimpinan.
\end{abstract}

\section{Kata Kunci : Gaya Kepemimpinan, Lingkungan Kerja Fisik, Kepuasan Kerja.}

\begin{abstract}
The purpose of this study to determine how much influence the leadership style and physical work environment on employee job satisfaction at PT. Brema Brata.

The type of research is quantitative research is analyzed using statistics the author makes the employees of PT. Brema Brata as a total population of 66 employees .. Data analysis using SPSS Version 22. Sampling technique using census method and data retrieval techniques such as validity test, reliability test, classical assumption test and multiple linear regression test and hypothesis test.

In general, test results of leadership style variables and physical work environment have a significant influence on job satisfaction in PT. Brema Brata. This means the hypothesis is acceptable, because the leadership style and work environment have a positive influence on job satisfaction. Among the two variables, the most significant influence was the leadership style variable.
\end{abstract}

Keywords: Leadership Style, Physical Work Environment, Job Satisfaction. 


\section{A. Pendahuluan}

Pemimpin sebagai panutan dalam organisasi, sehingga perubahan harus dimulai dari tingkat yang paling atas yaitu pemimpin itu sendiri maka dari itu, organisasi memerlukan pemimpin reformis yang mampu menjadi motor penggerak yang mendorong perubahan organisasi, manusia yang bekerja dalam sebuah perusahaan, menyumbangkan tenaganya baik fisik maupun pikiran dan mendapatkan imbalan atau balasan jasa sesuai dengan peraturan atau perjanjian di sebebut karyawan, karyawan merupakan aset yang paling penting dalam sebuah perusahaan.Peranan atasan atau sering disebut pimpinan sangatlah besar bagi keberhasilan perusahaan dalam mencapai tujuan, dari merekalah muncul gagasangagasan baru dan inovatif dalam pengembangan perusahaan namun tidak dapat dipungkiri bawahan mereka juga memiliki peranan yang tidak kalah penting.

Gaya kepemimpinan yang efektif dalam mengelola sumber daya manusia dalam suatu unit kerja akan berpengaruh pada perilaku kerja yang diindikasikan dengan peningkatan kepuasan kerja individu dan kinerja unit itu sendiri, yang pada akhirnya akan mempengaruhipeningkatan kepuasan kerja karyawan secara keseluruhan.Dalam menjalankan fungsi kepemimpinannya setiap pemimpin mempunyai perilaku dan cara tertentu dalam memimpin yang mana dari perilaku tersebut dapat menunjukan gaya kepemimpinannya, karena gaya kepemimpinan mencerminkan apa yang dilakukan pemimpin dalam mempengaruhi pengikutnya guna merealisasikan tujuan yang telah ditetapkan.

Manfaat lingkungan kerja fisik adalah menciptakan gairah kerja, sehingga produktifitas dan prestasi kerja meningkat.Sementara itu, manfaat yang diperoleh karena bekerja dengan orangorang yang termotivasi adalah pekerjaan dapat terselesaikan dengan tepat, yang artinya pekerjaan diselesaikan sesuai standar yang benar dan dalam skala waktu yang ditentukan.kepuasan kerja pada dasarnya bersifat individual.

Namun masih terdapat kendalakendala yang belum terselesaikan diantaranya belum optimalnya pemberian gaya kepemimpinan dibuktikan masih kurangnya dalam memberikan arahan yang sesuai kepada kayawannya, sehingga tidak sesuai dengan target yang diharapkan, hubungan kerja antara pemimpin dan bawahan yang kurang harmonis.Masalahmasalah yang terkait dengan lingkungan kerja fisik seperti, penataan ruang kerja yang kurang kondusif, kurangnya pencahayaan di setiap ruangan kamar mandi dan lorong-lorong, fasilitas kantor yang kurang memadai. Kepuasan kerja karyawanyapun masih ada kelemahanya yaitu ketidak stabilannya perputaran tenaga kerja (labour turn over) menunjukan distabilitas tenaga kerja merupakan gejala yang menunjukkan kurangnya semangat dan kegairahan kerja karyawan, yang menimbulkan disiplin pegawai mengalami penurunan.

Dari sekilas penjabaran materi diatas, penulis tertarik meneliti dengan judul "Pengaruh Gaya Kepemimpian dan Lingkungan Kerja Fisik Terhadap Kepuasan Kerja Pada PT. Brema Brata".

\section{B. Perumusan Masalah}

Berdasarkan latar belakang yang telah diungkapkan di atas, maka rumusan masalah dalam penelitian ini adalah :

1. Bagaimana gaya kepemimpinan pada PT. Brema Brata?

2. Bagaimana lingkungan kerja fisik pada PT. Brema Brata?

3. Bagaimana kepuasan kerja karyawan pada PT. Brema Brata? 
@ Prodi Manajemen Fakultas Ekonomi Universitas Pamulang

4. Bagaimana pengaruh gaya kepemimpinan dan lingkungan kerja fisik pada PT. Brema Brata?

\section{Kerangka Berpikir}

Kerangka berfikir penelitian ini dapat digambarkan sebagai berikut :

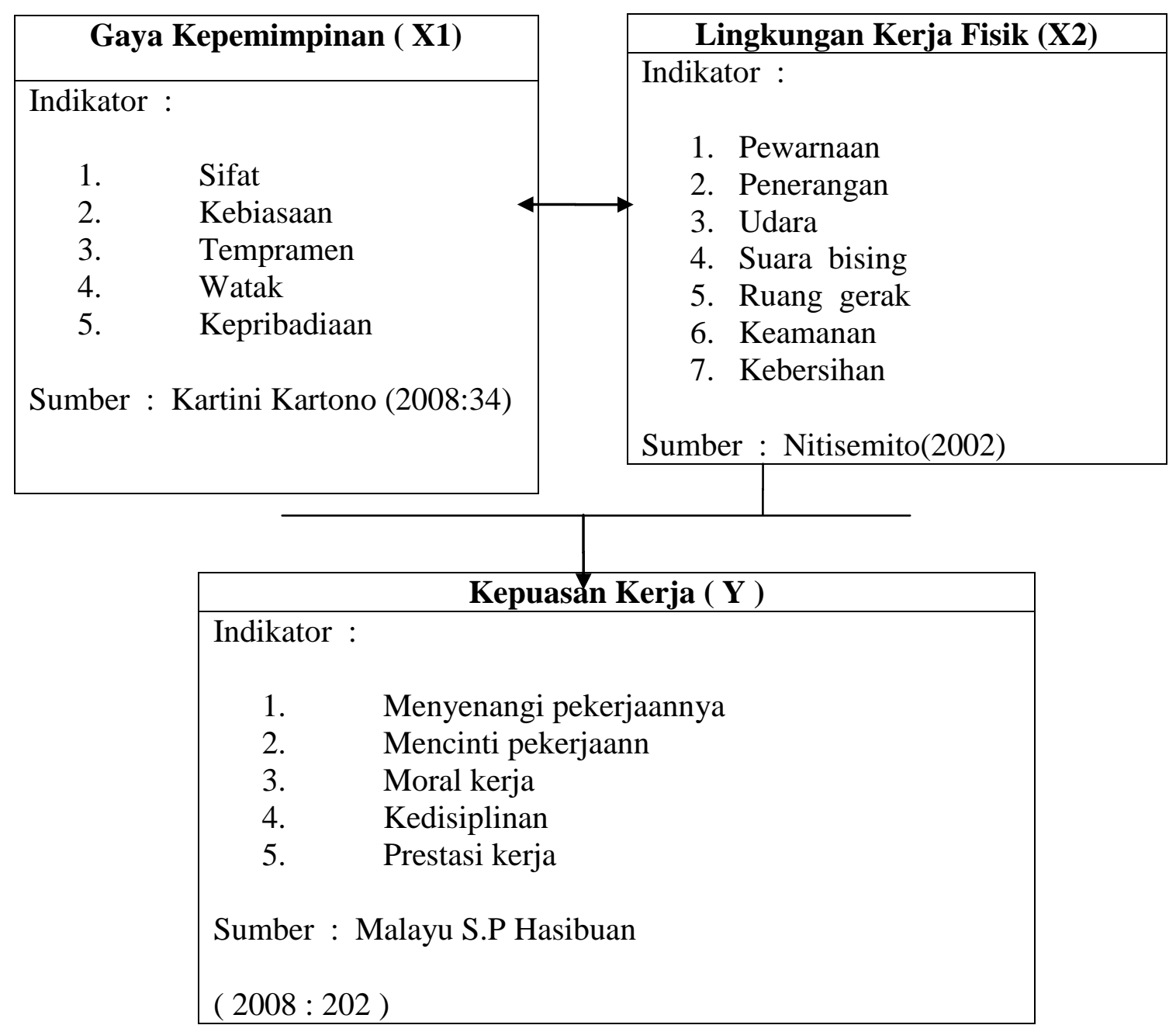

Gambar 1.1

\section{Landasan Teori}

\section{Gaya Kepemimpinan}

Gaya kepemimpinan merupakan norma perilaku yang dipergunakan oleh seseorang pemimpin pada saat mencoba mempengaruhi perilaku orang lain atau bawahan. Perwujudan tersebut biasanya membentuk suatu pola atau bentuk tertentu. Gaya kepemimpinan itu timbul berdasarkan cara bertindak atau bertingkah laku dari pimpinan yang bersangkutan.Gaya kepemimpinan mewakili filsafat, ketrampilan, dan

\section{Kerangka berfikir}

sikap pemimpin dalam politik.Menurut Heidjrachman dan Husnan, (2002:224) Gaya kepemimpinan adalah pola tingkah laku yang dirancang untuk mengintegrasikan tujuan organisasi dengan tujuan individu untuk mencapai tujuan tertentu. Pendapat lain menyebutkan bahwa Gaya Kepemimpinan adalah pola perilaku yang ditunjukkan oleh pemimpin dalam mempengaruhi orang lain, Menurut Ardana, dkk (2012:181). Pola perilaku tersebut bisa 
dipengaruhi oleh beberapa faktor seperti nilai-nilai, asumsi, persepsi, harapan, maupun sikap yang ada dalam diri pemimpin.

Berdasarkan uraian diatas,Indikator gaya kepemimpinan menurut Kartini Kartono (2008:34), sebagai berikut : sifat, kebiasaan, tempramen, watak dan kepribadian yang membedakan seorang pemimpin dalam berinteraksi dengan orang lain.

\section{Lingkungan Kerja Fisik}

Hubungan antara lingkungan fisik dengan kenyamanan kerja sangat signifikan.Pimpinan perusahaan dalam membebankan tugas dan tanggung jawab kepada karyawan hendaknya juga memperhatikan lingkungan kerja karyawan.Perusahaan dituntut harus mampu memberikan rasa aman dan kenyamanan bagi karyawan dalam bekerja.(Febriani dan Indrawati, 2013).Di dalam meningkatkan semangat kerja tidak terlepas dari lingkungan kerja yang mendukung seperti kualitas lingkungan fisik.Lingkungan kerja fisik memiliki kontribusi yang signifikan bagi kepuasan kerja karyawan (Holman, 2002), sehingga lingkungan kerja fisik karyawan memiliki efek yang kuat terhadap kepuasan kerja (Hurley et al., 2000).

Penilaian baik atau buruknya lingkungan kerja ditentukan oleh penilaian karyawannya. Seseorang mungkin menganggap lingkungan yang sama adalah buruk sedangkan yang lain menganggap baik. Hal ini disebabkan karena ada perbedaan pandangan masing-masing individu terhadap lingkungan kerja.Perbedaan ini dapat terjadi karena masing-masing individu mempunyai kebutuhan, kepentingan maupun harapan yang berbeda-beda antara satu dengan yang lain. Menurut Cary Cooper (Rini, 2002).Kondisi kerja yang buruk berpotensi menjadi penyebab karyawan mudah jatuh sakit, mudah stres, sulit berkonsentrasi, dan menurunnya kepuasan kerja.

$$
\text { Lingkungan kerja merupakan }
$$

lingkungan dimana pegawai melakukan pekerjaannya sehari-hari”.Lingkungan kerja yang kondusif memberikan rasa aman dan memungkinkan para pegawai untuk dapat berkerja optimal.Menurut Sedarmayanti (2007) "lingkungan kerja fisik adalah semua yang terdapat disekitar tempat kerja yang dapat mempengaruhi pegawai baik secara langsung maupun tidak langsung".Sedangkan menurut Sarwono (2005) "Lingkungan kerja fisik adalahtempat kerja pegawai melakukan aktivitasnya, lingkungannya kerja fisik mempengaruhi semangat dan emosi kerja para karyawan". Pendapat lain menyebutkan lingkungan kerja fisik adalah salah satu unsur yang harus digunakan oleh organisasi sehingga menimbulkan rasa nyaman, tentram, dan dapat meningkatkan hasil kerja yang baik untuk meningkatkan kinerja organisasi tersebut (Sihombing, 2004).

\section{Kepuasan Kerja}

Aktivitas hidup manusia beraneka ragam dan salah satu bentuk dari segala aktivitas yang ada adalah bekerja.Hal ini didorong oleh keinginan manusia untuk memenuhi adanya kebutuhan yang harus dipenuhi.Kepuasan kerja adalah sikap positifataupun negatif dari emosional karyawan memandang pekerjaannya baik yang ditunjukan dalam keadaan menyenangkan atau tidak (Handoko, 2001:193).Kepuasan kerja adalah sikap umum terhadap pekerjaan seseorang yang menunjukkan perbedaan antara jumlah penghargaan yang di terima pekerja dan jumlah yang mereka yakini seharusnya mereka terima. Wibowo (2010).Sedangkan menurut Hasibuan, (2009).Kepuasan kerja adalah sikap emosional yang menyenangkan dan mencintai 


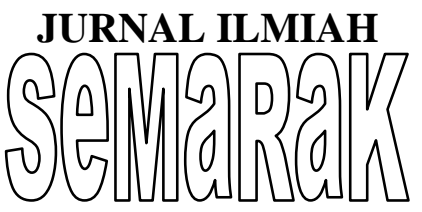

pekerjaanya.Sikap ini tercermin oleh moral kerja, kedisiplinan dan prestasi kerja.Kepuasan kerja dinikmati dalam pekerjaan, luar pekerjaan dan kombinasi dalam dan luar pekerjaan.(Wibowo, 2012:517). menyatakan kepuasan dapat ditingkatkan dan perpindahan (turnover) dapat diturunkan dengan cara membuat pekerjaan menjadi menyenangkan, membayar orang untuk jujur, yang sesuai dengan minat dan keahliannya serta menghindari kebosanan pekerjaan berulang-ulang.

Lima aspek kepuasan kerja diukur dengan Job Descriptive Index (JDI) yaitu pekerjaan itu sendiri (berhubungan dengan tanggung jawab, minat dan pertumbuhan); kualitas supervisi (terkait dengan bantuan teknis dan dukungan sosial); hubungan dengan rekan kerja (berkaitan dengan harmoni sosial dan respek); kesempatan promosi (terkait dengan kesempatan untuk pengembangan lebih jauh); dan pembayaran (yang terkait dengan pembayaran yang memadai dan persepsi keadilan) (Luthans, 2006).

\section{E. Metodologi Penelitian}

Jenis penelitian merupakan penelitian kuantitatif karena data penelitian berupa angka-angka yang nantinya akan dianalisis menggunakan statistik Penelitian ini bertujuan untuk mengetahui pengaruh gaya kepemimpinan dan lingkungan kerja fisik terhadap kepuasan kerja karyawan pada PT. Brema Brata

\section{Populasi Dan Sampel}

Pada penelitian ini, penulis karyawan PT. Brema Brata sebagai populasi totalnya berjumlah 66 karyawan. Adapun jumlah sampel diambil sample jenuh dimana seluruh populasi di jadikan sample. Pengumpulan data yang dipergunakan dalam penelitian ini antara lain observasi, penyebaran kuisioner dan dokumentasi. Dalam penelitian ini peneliti juga menggunakan kuesioner atau angket yang disebar pada responden (sampel penelitian) untuk mengetahui data tentang gaya kepemimpinan dan lingkungan kerja fisik terhadap kepuasan kerja karyawan. Dalam penilaian angket, digunakan skala likert dengan 5 alternatif jawaban yaitu sangat setuju, setuju, ragu-ragu, tidak setuju, sangat tidak setuju.

\section{Analisis Data}

Analisis data Analisis data yang digunakan dalam penelitian ini adalah uji validitas dan uji reliabilitas. Pengujian validitas menggunakan rumus korelasi pearson product moment, dengan ketentuan jika hiung $r>$ tabel $r$, berarti instrumen valid. Pengujian reliabilitas dalam penelitian ini menggunakan nilai Alpha Coanbach dengan ketentuan jika Alpha Croanbach ( hitung $r$ ) $>0,60$ berarti instrumen tersebut reliabel. Teknik analsis data antara lain uji asumsi klasik dan analisis regresi ganda. Uji asumsi klasik terdiri dari uji normalitas, uji multikolinearitas, uji heteroskedastisitas, uji autokorelasi.

\section{Uji Normalitas}

Data yang telah terkumpul harus diuji normalitasnya terlebih dahulu guna mengetahui apakah data penelitian berasal dari populasi yang sebarannya normal atau tidak. Pengujian normalitas menggunakan One-sample Kolmogorov-Smirnov Test dengan SPSS 22.0 for windows. Dengan ketentuan, jika nilai Asymp Sig > 0,05 maka data berdistribusi normal.

\section{Uji Multikolinearitas}

Uji Multikolinearitas dilakukan untuk mengetahui ada tidaknya kemiripan yang dimiliki oleh satu variabel independent dengan variabel independen yang lain dalam satu model. Pengujian multikolinearitas dalam penelitian ini menngunakan VIF (Variance Inflation Factor), dengan ketentuan jika nilai tolerance $>0,1$ dan nilai $\mathrm{VIF}<10$, maka 


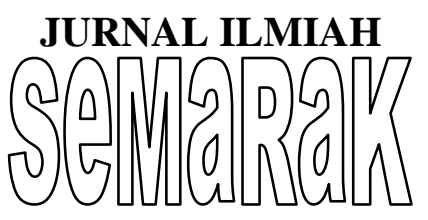

\section{P-ISSN 2615-6849}

Jurnal Semarak,Vol. 1,No.1,Februari 2018 , Hal (42-53)

@ Prodi Manajemen Fakultas Ekonomi Universitas Pamulang

data tidak maka data tidak mengalami multikolinearitas.

\section{Uji Heterokedastisitas}

Pengujian dilakukan untuk mengetahui apakah terjadi penyimpangan model karena gangguan variabel yang berbeda antar observasi ke observasi lain. Untuk mengetahui apakah terjadi heteroskedastisitas atau tidak, dapat dilihat pada gambar Scattreplot, jika pada gambar scatterplot tidak ada pola yang jelas serta titiktitik menyebar diatas dan dibawah angka 0 pada sumbu Y, maka tidak terjadi heterokedastisistas.

\section{Analisis Regresi Ganda}

Teknik analisis regresi ganda dipergunakan untuk mengetahui pengaruh gaya kepemimpinan dan lingkungan kerja fisik terhadap kepuasan kerja karyawan PT. Brema Brata. Dengan persamaan regresi $Y=a+b_{1} X_{1}+X_{2} b_{2}$

Teknik pengujian hipotesis menggunakan uji parsial dan uji simultan dengan teknik probabilitas, dengan cara membandingkan nilai probabilitas Sig dengan taraf signifikansi 0,05 . Jika nilai probabilitas sig $<0,05$ maka signifikan.

\section{Koefisien Determinasi}

Pengujian koefisien determinasi bertujuan untuk mengetahui besarnya pengaruh antar variabel. Nilai koefisien determinasi menunjukkan presentase variasi nilai variabel dependen yang dapat dijelaskan oleh persamaan regresi yang dihasilkan.

\section{F. Analisis Hasil Penelitian dan Pembahasan}

Hasil penelitian ini berdasarkan data primer dan sekunder yang telah diolah oleh peneliti untuk mengetahui apakah ada pengaruh antara gaya kepemimpinan dan lingkungan kerja fisik terhdap kepuasan kerja pada PT. Brema Brata

\section{Karakteristik Responden}

Objek dan populasi dalam penelitian ini adalah karyawan PT. Brema Brata dengan jumlah populasi 66 orang.Dalam penelitian ini terdapat 2 karakteristik responden yang dikelompokkan menurut jenis kelamin dan umur. Gambaran mengenai karakteristik responden dijelaskan pada tabel berikut ini :

Tabel 3.2 Karakteristik Responden Berdasarkan Jenis Kelamin

\begin{tabular}{|c|c|c|}
\hline Jenis Kelamin & Frekuensi & Persentase \\
\hline Laki - Laki & 35 & $53 \%$ \\
\hline Wanita & 31 & $47 \%$ \\
\hline Tidak Mengisi Data & - & $0 \%$ \\
\hline Total & $\mathbf{6 6}$ & $\mathbf{1 0 0} \%$ \\
\hline
\end{tabular}

Sumber: Data primer diolah, 2016

Tabel 1.2 di atas menunjukan jumlah sebanyak 35 orang $(53 \%)$ dan responden yang berjenis kelamin perempuan responden yang berjenis kelamin laki-laki

sebanyak 31 orang $(47 \%)$.




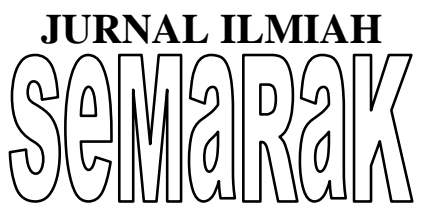

urnal Semarak,Vol. 1,No.1,Februari 2018 , Hal (42-53)

@ Prodi Manajemen Fakultas Ekonomi Universitas Pamulang

Tabel 3.3 Karakteristik Responden Berdasarkan Umur

\begin{tabular}{|c|c|c|}
\hline Umur & Frekuensi (orang ) & Persentase \\
\hline $20-30$ Tahun & 7 & $10.6 \%$ \\
\hline $31-40$ Tahun & 20 & $30.3 \%$ \\
\hline $41-60$ Tahun & 27 & $40.9 \%$ \\
\hline >- 60 Tahun & 12 & $18.2 \%$ \\
\hline Tidak Mengisi Data & - & $0 \%$ \\
\hline Total & $\mathbf{6 6}$ & $\mathbf{1 0 0 . 0} \%$ \\
\hline
\end{tabular}

\section{Sumber: Data primer diolah, 2016}

Tabel 1.3 di atas menunjukan jumlah responden yang berumur $20-30$ tahun sebanyak 7 orang $(10.6 \%)$, responden yang berumur 31 - 40 tahun sebanyak 20 orang $(30.3 \%)$, responden yang berumur 41 - 60 tahun sebanyak 27 orang $(40.9 \%)$ responden yang berumur $>60$ tahun sebanyak 12 orang (18.2 \%). Hal ini menggambarkan bahwa responden paling banyak berada di rentang umur 41 - 60 tahun yaitu 27 Orang (40.9\%).

\section{Deskripsi Variabel Penelitian}

Setelah semua data terkumpul, langkah berikutnya adalah melakukan tabulasi data untuk membuat tingkatan tanggapan responden mengenai kepuasan kerja berdasarkan variabel dari gaya kepemimpinan dan lingkungan kerja fisik. Dimana setiap butir pernyataan akan diuji pada 66 responden. Seluruh tanggapan responden akan menetukan hasil dari penelitian ini.

a. Deskripsi Variabel Gaya Kepemimpinan (X1)

\begin{tabular}{|c|c|c|c|c|c|c|c|c|c|c|c|}
\hline \multirow{3}{*}{ Indikator } & \multicolumn{11}{|c|}{ Jawaban Responden } \\
\hline & \multicolumn{2}{|c|}{ SJ } & \multicolumn{2}{|c|}{$\mathbf{J}$} & \multicolumn{2}{|c|}{ C } & \multicolumn{2}{|c|}{ B } & \multicolumn{2}{|c|}{ SB } & \multirow[t]{2}{*}{ Mean } \\
\hline & $\mathbf{F}$ & $\%$ & $\mathbf{F}$ & $\%$ & $\mathbf{F}$ & $\%$ & $\mathbf{F}$ & $\%$ & $\mathbf{F}$ & $\%$ & \\
\hline X1.1 & - & - & - & - & 5 & 7.6 & 24 & 36.4 & 37 & 56.1 & 4.4848 \\
\hline $\mathrm{X} 1.2$ & - & - & - & - & 10 & 15.2 & 31 & 47.0 & 25 & 37.9 & 4.2273 \\
\hline $\mathrm{X} 1.3$ & - & - & - & - & 7 & 10.6 & 28 & 42.4 & 31 & 47.0 & 4.3636 \\
\hline X1.4 & - & - & 1 & 1.5 & 9 & 13.6 & 36 & 54.5 & 20 & 30.3 & 4.1364 \\
\hline $\mathrm{X} 1.5$ & - & - & 3 & 4.5 & 11 & 16.7 & 40 & 60.6 & 12 & 18.2 & 4.9242 \\
\hline $\mathrm{X} 1.6$ & - & - & - & - & 7 & 10.6 & 28 & 42.4 & 31 & 47.0 & 4.3636 \\
\hline $\mathrm{X} 1.7$ & - & - & - & - & 10 & 15.2 & 31 & 47.0 & 25 & 37.9 & 4.2273 \\
\hline $\mathrm{X} 1.8$ & - & - & - & - & 3 & 4.5 & 31 & 47.0 & 32 & 48.5 & 4.4394 \\
\hline Total & & & & & & 4.39 & & & & & \\
\hline
\end{tabular}

Tabel 3.4 Tanggapan Responden Terhadap Variabel Gaya Kepemimpinan

Sumber: Data Primer, 2016 


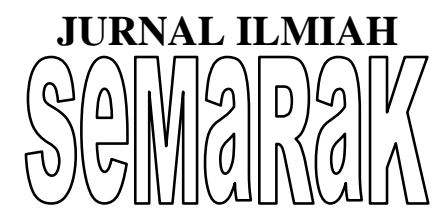

b. Deskripsi Variabel Lingkungan Kerja Fisik (X2)

\begin{tabular}{|c|c|c|c|c|c|c|c|c|c|c|c|}
\hline \multirow{3}{*}{ Indikator } & \multicolumn{11}{|c|}{ Jawaban Responden } \\
\hline & \multicolumn{2}{|c|}{ SJ } & \multicolumn{2}{|c|}{$\mathbf{J}$} & \multicolumn{2}{|c|}{$\mathrm{C}$} & \multicolumn{2}{|c|}{ B } & \multicolumn{2}{|c|}{ SB } & \multirow{2}{*}{ Mean } \\
\hline & $\mathbf{F}$ & $\%$ & $\mathbf{F}$ & $\%$ & $\mathbf{F}$ & $\%$ & $\mathbf{F}$ & $\%$ & $\mathbf{F}$ & $\%$ & \\
\hline $\mathrm{X} 2.1$ & - & - & 1 & 1.5 & 9 & 13.6 & 39 & 59.1 & 17 & 25.8 & 4.0909 \\
\hline $\mathrm{X} 2.2$ & - & - & 12 & 18.2 & 7 & 10.6 & 31 & 47.0 & 16 & 24.2 & 3.7727 \\
\hline $\mathrm{X} 2.3$ & - & - & 4 & 6.1 & 7 & 10.6 & 32 & 48.5 & 23 & 34.8 & 4.1212 \\
\hline $\mathrm{X} 2.4$ & - & - & 10 & 15.2 & 8 & 12.1 & 31 & 47.0 & 17 & 25.8 & 3.8333 \\
\hline $\mathrm{X} 2.5$ & - & - & 6 & 9.1 & 12 & 18.2 & 28 & 42.4 & 20 & 30.3 & 3.9394 \\
\hline $\mathrm{X} 2.6$ & - & - & 12 & 18.2 & 7 & 10.6 & 31 & 47.0 & 16 & 24.2 & 3.7727 \\
\hline $\mathrm{X} 2.7$ & - & - & 6 & 9.1 & 12 & 18.2 & 28 & 42.4 & 20 & 30.3 & 3.9394 \\
\hline $\mathrm{X} 2.8$ & - & - & 1 & 1.5 & 10 & 15.2 & 31 & 47.0 & 24 & 36.4 & 4.1818 \\
\hline X2.9 & - & - & - & - & 8 & 12.1 & 36 & 54.5 & 22 & 33.3 & 4.1212 \\
\hline Total & & & & & & 3.974 & & & & & \\
\hline
\end{tabular}

Tabel 3.5 Tanggapan Responden Terhadap Variabel Lingkungan Kerja Fisik Sumber: Data Primer, 2016

c. Deskripsi Variabel Kepuasan Kerja (Y)

\begin{tabular}{|c|c|c|c|c|c|c|c|c|c|c|c|}
\hline \multirow{3}{*}{ Indikator } & \multicolumn{11}{|c|}{ Jawaban Responden } \\
\hline & \multicolumn{2}{|c|}{ SJ } & \multicolumn{2}{|c|}{$\mathbf{J}$} & \multicolumn{2}{|c|}{$\mathrm{C}$} & \multicolumn{2}{|c|}{ B } & \multicolumn{2}{|c|}{ SB } & \multirow[t]{2}{*}{ Mean } \\
\hline & $\mathbf{F}$ & $\%$ & $\mathbf{F}$ & $\%$ & $\mathbf{F}$ & $\%$ & $\mathbf{F}$ & $\%$ & $\mathbf{F}$ & $\%$ & \\
\hline Y1 & - & - & 6 & 9.1 & 12 & 18.2 & 28 & 42.4 & 20 & 30.3 & 3.9394 \\
\hline Y2 & - & - & 1 & 1.5 & 9 & 13.5 & 39 & 59.1 & 17 & 25.8 & 4.0909 \\
\hline Y3 & - & - & 10 & 15.2 & 8 & 12.1 & 31 & 47.0 & 17 & 25.8 & 3.8333 \\
\hline Y4 & - & - & 6 & 9.1 & 12 & 18.2 & 28 & 42.4 & 20 & 30.2 & 3.9394 \\
\hline Y5 & - & - & 1 & 1.5 & 9 & 13.6 & 39 & 59.1 & 17 & 25.8 & 4.0909 \\
\hline Y6 & - & - & 12 & 18.2 & 7 & 10.6 & 31 & 47.0 & 16 & 24.2 & 3.7727 \\
\hline Y7 & - & - & 4 & 6.1 & 7 & 10.6 & 32 & 48.5 & 23 & 34.8 & 4.1212 \\
\hline Y8 & - & - & 10 & 15.2 & 8 & 12.1 & 31 & 47.0 & 17 & 25.8 & 3.8333 \\
\hline Y9 & - & - & 10 & 15.2 & 8 & 12.1 & 31 & 47.0 & 17 & 25.8 & 3.8333 \\
\hline Y10 & & & 6 & 9.1 & 12 & 18.2 & 28 & 42.4 & 20 & 30.3 & 3.9394 \\
\hline Total & & & & & & 3.93 & & & & & \\
\hline
\end{tabular}

\section{Tabel 3.6 Tanggapan Responden Terhadap Variabel Kepuasan Kerja}

Sumber: Data Primer, 2016

\section{Uji Validitas dan Uji Reliabilitas}

Uji validitas digunakan untuk mengukur sah atau valid tidaknyasuatu kuesioner dan Uji reliabilitas dimaksudkan untuk mengukur suatukuesioner yang merupakan indikator dari variabel. 


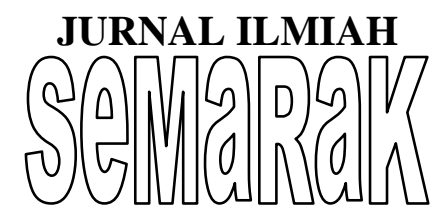

\begin{tabular}{|c|c|c|c|c|}
\hline No & Konsep & VariabelPenelitian & Corrected Item & Status \\
\hline \multirow{8}{*}{1} & \multirow{8}{*}{$\begin{array}{c}\text { Gaya } \\
\text { Kepemimpinan } \\
(\mathrm{X} 1)\end{array}$} & $\mathrm{X} 1.1$ & 0.442 & Valid \\
\hline & & $\mathrm{X} 1.2$ & 0.607 & Valid \\
\hline & & $\mathrm{X} 1.3$ & 0.628 & Valid \\
\hline & & $\mathrm{X} 1.4$ & 0.478 & Valid \\
\hline & & $\mathrm{X} 1.5$ & 0.428 & Valid \\
\hline & & X1.6 & 0.628 & Valid \\
\hline & & $\mathrm{X} 1.7$ & 0.607 & Valid \\
\hline & & $\mathrm{X} 1.8$ & 0.426 & Valid \\
\hline \multirow{9}{*}{2} & \multirow{9}{*}{$\begin{array}{l}\text { Lingkungan } \\
\text { Kerja Fisik } \\
\text { (X2) }\end{array}$} & $\mathrm{X} 2.1$ & 0.326 & Valid \\
\hline & & $\mathrm{X} 2.2$ & 0.617 & Valid \\
\hline & & $\mathrm{X} 2.3$ & 0.474 & Valid \\
\hline & & $\mathrm{X} 2.4$ & 0.637 & Valid \\
\hline & & $\mathrm{X} 2.5$ & 0.652 & Valid \\
\hline & & $\mathrm{X} 2.6$ & 0.617 & Valid \\
\hline & & $\mathrm{X} 2.7$ & 0.652 & Valid \\
\hline & & $\mathrm{X} 2.8$ & 0.362 & Valid \\
\hline & & $\mathrm{X} 2.9$ & 0.312 & Valid \\
\hline \multirow{10}{*}{2} & \multirow{10}{*}{$\begin{array}{c}\text { Kepuasan } \\
\text { Kerja } \\
(\mathbf{Y})\end{array}$} & $\mathrm{Y} 1$ & 0.808 & Valid \\
\hline & & Y2 & 0.474 & Valid \\
\hline & & Y3 & 0.837 & Valid \\
\hline & & Y4 & 0.808 & Valid \\
\hline & & Y5 & 0.474 & Valid \\
\hline & & Y6 & 0.437 & Valid \\
\hline & & Y7 & 0.306 & Valid \\
\hline & & Y8 & 0.837 & Valid \\
\hline & & Y9 & 0.837 & Valid \\
\hline & & Y10 & 0.808 & Valid \\
\hline
\end{tabular}

Tabel 3.7 Hasil Uji Validitas

Sumber: Data primer, 2016

Berdasarkan tabel hasil uji validitas di atas, diketahui bahwa seluruh item pernyataan yang digunakan dalam penelitian ini untuk mengukur variabel gaya kepemimpinan, variabel lingkungan kerja fisik dan variable kepuasan kerja adalah valid, yang ditunjukkan dengan nilai dari masingmasing item pernyataan berdasarkan kolom Corrected Item- Total Correlation memiliki nilai koefisien korelasi positif dan lebih besar dari 0,3.
Uji reliabilitas dimaksudkan untuk mengukur suatu kuesioner yangmerupakan indikator dari variabel. Reliabilitas diukur dengan uji statistic cronbach's alpha $(\alpha)$. Suatu variabel dikatakan reliable jika memberikannilai cronbach's alpha> 0,60. Hasil uji realibilitas dapat dilihat pada table berikut:

\section{a. Uji Reliabilitas}


JURNAL ILMIAH

(5)

P-ISSN 2615-6849

Jurnal Semarak,Vol. 1,No.1,Februari 2018 , Hal (42-53)

@ Prodi Manajemen Fakultas Ekonomi Universitas Pamulang

\begin{tabular}{|l|l|l|l|l|}
\hline No & Variabel Penelitian & AlphaCronbach's & $\begin{array}{c}\text { Alpha } \\
\text { ToleransiItem }\end{array}$ & \multicolumn{1}{|c|}{ Status } \\
\hline 1 & Gaya Kepemimpinan & .822 & 0.6 & Reliabel \\
\hline 2 & $\begin{array}{l}\text { Lingkungan Kerja } \\
\text { Fisik }\end{array}$ & .813 & 0.6 & Reliabel \\
\hline 3 & Kepuasan Kerja & .906 & 0.6 & Reliabel \\
\hline
\end{tabular}

Tabel 3.8 Hasil Uji Reliabilitas

b. Uji Hipotesis

Pengujian Hipotesis Secara Parsial (Uji t)

\begin{tabular}{|c|c|c|c|c|c|c|}
\hline & Model & $\begin{array}{l}\text { UnstandardizedCoe } \\
\text { fficients }\end{array}$ & & $\begin{array}{l}\text { StandardizedCoe } \\
\text { fficients }\end{array}$ & $\mathrm{t}$ & Sig \\
\hline & & $\mathrm{B}$ & Std. Error & Beta & & \\
\hline \multirow[t]{8}{*}{1} & (Constant) & 1.608 & 4.266 & & .377 & .708 \\
\hline & Gaya & 281 & .102 & .230 & $\begin{array}{c}2.75 \\
9\end{array}$ & .008 \\
\hline & Kepemimpinan & & & & & \\
\hline & Lingkungan & .755 & .904 & .637 & $\begin{array}{c}8.06 \\
3\end{array}$ & .000 \\
\hline & Kerja Fisik & & & & & \\
\hline & R Squere $\left(\mathrm{R}^{2}\right)$ & & $=0.603$ & F-Hitung & & $\begin{array}{c}= \\
47.76 \\
1\end{array}$ \\
\hline & $\begin{array}{l}\text { Adjusted R } \\
\text { Square }\end{array}$ & & $=0.590$ & Constanta & & $\begin{array}{c}= \\
1.608\end{array}$ \\
\hline & Multiple R & & $=0.776$ & Sig.F & & $\begin{array}{c}= \\
0.000\end{array}$ \\
\hline
\end{tabular}

d. Pengujian Hipotesis Secara Simultan (Uji F)

ANOVAb

\begin{tabular}{|c|c|c|c|c|c|}
\hline Model & $\begin{array}{c}\text { Sum of } \\
\text { Squares }\end{array}$ & Df & Mean Square & F & Sig. \\
\hline Regression & 1720.817 & 2 & 860.408 & 47.761. & $.000 \mathrm{a}$ \\
\hline Residual & 1134.941 & 63 & 18.015 & & \\
\hline Total & 2855.758 & 65 & & & \\
\hline
\end{tabular}

a.Predictors: (Constant), X2,X1 b. Dependent Variable: $Y$

e. Pengujian Hipotesis Secara Simultan (Uji F)

ANOVAb

\begin{tabular}{|c|c|c|c|c|c|}
\hline Model & $\begin{array}{c}\text { Sum of } \\
\text { Squares }\end{array}$ & Df & Mean Square & F & Sig. \\
\hline Regression & 1720.817 & 2 & 860.408 & 47.761. & $.000 \mathrm{a}$ \\
\hline Residual & 1134.941 & 63 & 18.015 & & \\
\hline Total & 2855.758 & 65 & & & \\
\hline
\end{tabular}

a.Predictors: (Constant), X2,X1 b. Dependent Variable: Y 


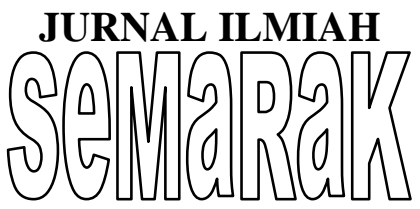

P-ISSN 2615-6849

Jurnal Semarak,Vol. 1,No.1,Februari 2018 , Hal (42-53)

@ Prodi Manajemen Fakultas Ekonomi Universitas Pamulang

\section{Pembahasan}

Secara umum hasil pengujian variabel gaya kepemimpinan dan lingkungan kerja fisik mempunyai pengaruh yang signifikan terhadap kepuasan kerja di PT. Brema Brata. Hal ini berarti hipotesis dapat diterima, karena gaya kepemimpinan dan lingkungan kerja memiliki pengaruh positif terhadap kepuasan kerja. Diantara dua variabel,pengaruh paling signifikan adalah variabel gaya kepemimpinan.

Untuk menghasilkan kepuasan kerja yang maksimal faktor yang paling berpengaruh adalah gaya kepemimpinan yang telah di uji memiliki pengaruh sebesar 59\% terhadap kepuasan kerja dan sisanya $41 \%$ dipengaruhi oleh lingkunaga kerja fisik. Sebagaimana yang sudah dibahas sebelumnya gaya kepemimpinan dan lingkungan kerja fisik didefinisikan sebagai persepsi karyawan tentang kesejahteraan mental dan fisiknya ketika bekerja. Ada dua pandangan mengenai maksud dari gaya kepemimpinan dan linkungan kerja fisik. Pertama, adalah sejumlah keadaan dan praktek dari organisasi berjalan dengan baik.Sementara yang kedua, adalah persepsi karyawan bahwa mereka ingin merasa aman, puas, dan mendapatkan kesempatan untuk tumbuh dan berkembang sebagai layaknya manusia (cacsio, 2006).Faktor yang meningkatkan kepuasan kerja karyawan sangat berharga, maka perusahaan bertanggung jawab untuk memilih pemimpin yang baik dan membina karyawan agar bersedia memberikan sumbangannya secara optimal untuk mencapai tujuan perusahaan (Pruijt, 2003).

Dari data yang sudah didapatkan sebelumnya peneliti dapat mengetahui bahwa gaya kepemimpinan dan lingkungan kerja fisik telah diterapkan dengan baik oleh pemangku kepentingan PT. Brema Brata dibuktikan dengan tanggapan responden terhadap variabel $X 1, X 2$ berada pada range skor keempat (Tinggi).

\section{G. Kesimpulan}

Penelitian ini bertujuan untuk mengetahui pengaruh gaya kepemimpinan dan lingkungan kerja fisik terhadap kepuasan kerja di PT. Brema Brata. Berdasarkan analisis serta pembahasan maka dapat ditarik kesimpulan sebagai berikut :

1. Dari hasil kuesioner di dapati bahwa hasil Uji $\mathrm{T}$, variable gaya kepemimpinan dan lingkungan kerja fisik $(X 1, X 2)$ berpengaruh secara signifikan terhadap kepuasan kerja (Y), untuk menghasilkan kepuasan kerja yang maksimal faktor yang paling berpengaruh adalah gaya kepemimpinan yang telah di uji memiliki pengaruh sebesar 59\% terhadap kepuasan kerja dan sisanya $41 \%$ dipengaruhi oleh lingkunaga kerja fisik.

2. Pada bagian dari hasil analisis deskriptif dan perhitungan skor variabel $\mathrm{X}$ dan $\mathrm{Y}$ peneliti menemukan bahwa karyawan di PT. Brema Brata mengetahui tugas dan tanggung jawabnya dengan jelas.Karyawan juga merasa nyaman saat bekerja, serta arahahan kerja yang diberikan jelas dan masuk akal.

3. Pada bagian deskriptif peneliti juga mendapatkan jawaban responden dengan skor rendah yaitu mengenai banyak responden tidak mendapatkan fasilitas kantor yang memadai di PT. Brema Brata. Pertanyaan pada kuesiner ini mendapatkan skor rendah berada pada range dua. hal ini kemungkinan dikarenakan keterbatasan fasilitas yang diberikan kepada karyawan. Tetapi secara umum gayakepemimpinan dan lingkungan kerja fisik yang terdiri dari 35 item pertanyaan kuesioner berada pada range keempat (tinggi). 


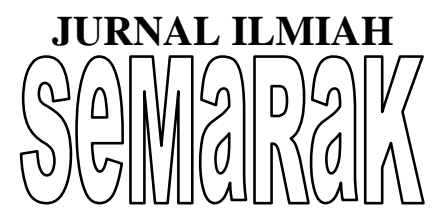

P-ISSN 2615-6849

Jurnal Semarak,Vol. 1,No.1,Februari 2018 , Hal (42-53)

@ Prodi Manajemen Fakultas Ekonomi Universitas Pamulang

\section{H. Daftar Pustaka}

Handoko, T. Hani. 2001. Manajemen Personalia dan Sumber Daya Manusia. Edisi Kedua. Yogyakarta: BPFE UGM

Hasibuan. 2009. Manajemen Sumber Daya Manusia. Bumi Askara : Bandung.

Hasibuan, Melayu SP, 2008. Manajemen Sumber Daya Manusia. Jakarta:PT. Bumi Aksara Hasibuan, Melayu SP, 2001. Manajemen Sumber Daya Manusia, Edisi Revisi : Bumi Aksara

Hasibuan, S. P. M. 2003, Manajemen Sumber Daya Manusia. Jakarta, Cetakan Keenam, Penerbit : PT. Bumi Aksara.

Heidrajrahcman dan Husnan Suad (2002) "Manajemen Personalia", Yogyakarta, BPFE Husaini Usman dan Purnomo, 2008. Metodologi Penelitian Sosial. Penerbit PT Bumi Aksara : Jakarta.

Luthans, F,

2006, Perilaku Organisasi, Edisi 10, Penerbit Andi, Yogyakarta.

Mardiana. 2005. Manajemen Produksi. Jakarta : IPWI

Nitisemito, Alex S, 2001. Manajemen Personalia. Penerbit Bumi Askara, Bandung. Robbins, Stephen P, 2006, Perilaku Organisasi, Edisi kesepuluh, PT Indeks Jakarta.

Sedarmayati. 2007. Manajemen Perkantoran Efektif. UPP STIM YKPN. Yogyakarta 